\title{
The use of Le Fort I Approach in the resection of an extensive ossifying fibroma
}

\author{
Eduardo Costa Studart Soares • \\ José Rômulo de Medeiros • Tácio Pinheiro Bezerra • \\ Carlos Bruno Pinheiro Nogueira • \\ Fábio Wildson Gurgel Costa • \\ Alexandre Simões Nogueira
}

Received: 5 February 2012 / Accepted: 18 August 2012/Published online: 30 August 2012

(C) Springer-Verlag 2012

\begin{abstract}
Introduction Ossifying fibroma (OF) is a well-defined benign neoplasm characterized by slow growth and predilection for the posterior mandible site, usually treated by conservative surgical approaches. In this context, Le Fort I Approach (LFIA) has been increasingly used providing good visualization and an easy access to the lesion. It also allows removal of the lesion quickly. Although there are case reports using LFIA for the management of benign neoplasms, odontogenic cysts and tumors of the middle third of face, to our knowledge, only one article describes the use of surgical LFIA for OF of the maxilla. Thus, the objective of this study was to report the second paper on the use of horizontal osteotomy of the maxilla in the resection of an extensive OF and conduct a brief literature review on this surgical approach.

Case report The following case report describes a 33-yearold man who was diagnosed with OF. Oral examination showed a painless swelling of hard consistency, covered
\end{abstract}

E. C. Studart Soares · J. R. de Medeiros · T. P. Bezerra •

C. B. P. Nogueira

Oral and Maxillofacial Surgery Service, Walter Cantídio

University Hospital, Federal University of Ceará,

Fortaleza, Brazil

F. W. G. Costa $\cdot$ A. S. Nogueira

Division of Oral Radiology and Stomatology,

Department of Clinical Dentistry, School of Dentistry,

Federal University of Ceará Campus Sobral,

Fortaleza, Brazil

J. R. de Medeiros ( $\square)$

Hospital Universitário Walter Cantídio-Universidade

Federal do Ceará,

Rua Capitão Francisco Pedro, 1290-Rodolfo Teófilo,

Fortaleza, Ceará, Brazil 60430-370

e-mail: joseromulo@yahoo.com.br by normal mucosa in edentulous alveolar ridge of the maxillary posterior region of the right side. Tomographic slices revealed that the image with mixed density had a centrifugal growth, with expansion of the buccal and lingual cortical with an upper displacement of the maxillary sinus. The patient was admitted to the hospital for surgical resection of the lesion via LFIA. Satisfactory functional results were obtained after 18-month follow-up period. In addition, no recurrence or clinical complaints were noted.

Discussion LFIA shall be considered as a feasible option when planning surgery for removal of extensive benign lesions located in midfacial region because it is a predictable technique and routinely performed by the oral and maxillofacial surgeons.

Keywords Oral Surgery $\cdot$ Le Fort Osteotomy $\cdot$ Ossifying Fibroma

\section{Background}

Ossifying fibroma (OF) is a well-defined benign neoplasm formed by different fibrocellular tissue and mineralized material. Female patients aging between 20 and 40 years are the most affected. Clinical presentation is commonly an asymptomatic slow-growing swelling, mainly affecting the posterior mandibular region. Radiographically, this condition is characterized as a well-defined lesion with radiopaque and radiolucent areas [1-3]. Surgical excision is the treatment of choice [4].

The horizontal maxillary osteotomy, also known as Le Fort I Approach (LFIA), is a surgical procedure which provides low morbidity and maintenance of preoperative occlusion. It is commonly used for resection of tumors with 
difficult access, such as those located at the skull base and cervical vertebrae $[5,6]$. This osteotomy was first described by Langenbeck in 1861 for the treatment of a tumor located in the pterygopalatine fossa [6]. Although there are case reports using LFIA in the management of benign neoplasms, odontogenic cysts and tumors of the midface [5], only Sailer et al. [5] described the use of this technique in maxilla to treating OF. Thus, the aim of the present study was to report the second paper using LFIA in an extensive maxillary OF and to conduct a brief literature review.

\section{Case report}

A 33-year-old man referred to the outpatient clinic of the Department of Oral and Maxillo-Facial Surgery at the Walter Cantídio University Hospital, Fortaleza, Brazil. He presented with a 10-year history of a painless "lump on the mouth bone." Extraoral examination showed a slight swelling in the right buccal region. Oral examination showed a hard swelling in the right posterior maxilla measuring approximately $4 \mathrm{~cm}$ and covered with normal mucosa (Fig. 1). Imaging exams demonstrated a mixture of radiodensity and radiolucency and a well-defined large osteolytic lesion involving the right maxilla, maxillary sinus, and alveolar bone. Additionally, centrifugal growth pattern was observed (Fig. 2). Incisional biopsy revealed the diagnosis of OF. The tumor was excised under general anesthesia. Surgical phases included: (1) maxillary transoral approach, (2) standardized Le Fort I osteotomy, (3) 2.0-mm titanium plates adjustment, (4) downfracture and lesion exposure, (5) a 5-mm margin establishment beyond the lesion using a reciprocating saw parallel to the intermaxillary suture surrounding the lesion (Fig. 3), (6) mass mobilization with chisels, (7) specimen resection, (8) placement of pre-modeled fixation plates (Fig. 4), and (9) surgical wound suture. Satisfactory

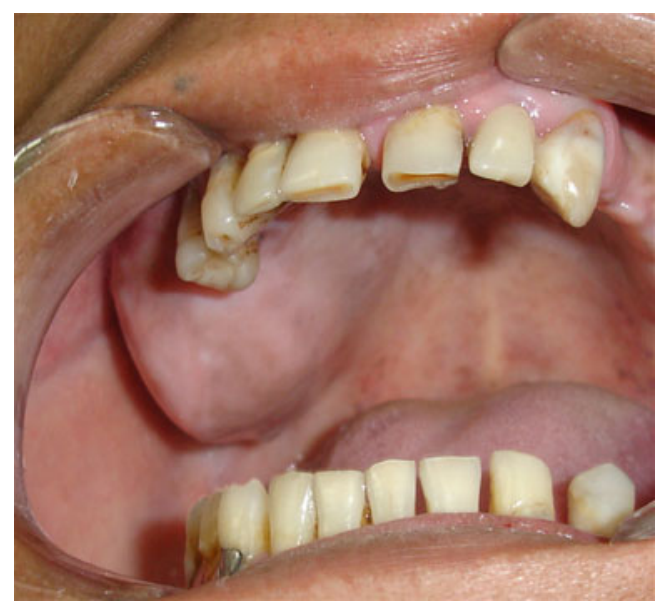

Fig. 1 Clinical aspects of the lesion in maxilla recovered by normal mucosa

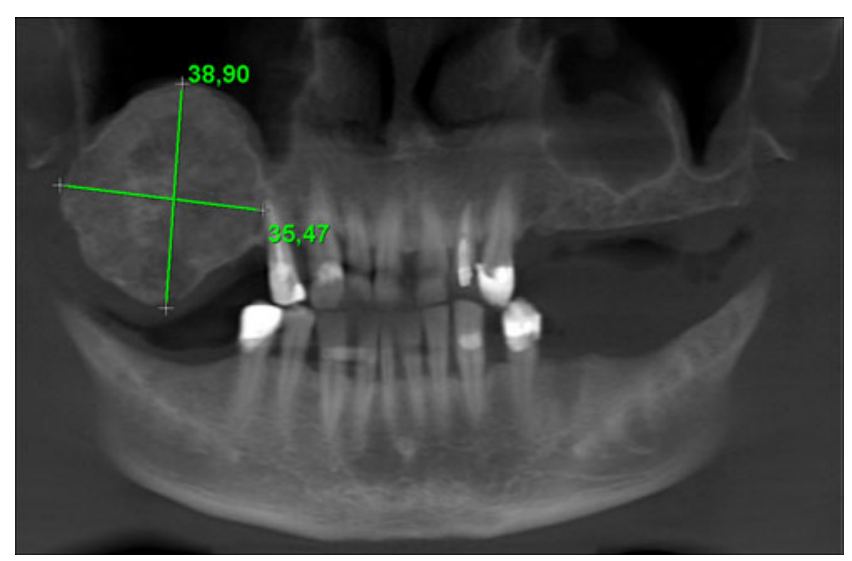

Fig. 2 Cone beam tomographic scan showing a large maxillary lesion with mixed density

functional results were obtained after a period of 18-month follow-up. In addition, no recurrence or clinical complaints were noted (Fig. 5).

\section{Discussion}

Different approaches for tumors removal from midface, pterygopalatine, skull base, and nasopharynx regions have been described using in the most of the cases extraoral access through Weber-Ferguson incision [5]. CaldwellLuc approach is a direct intraoral technique that uses anterior and lateral walls of the maxillary sinus to have access to lesions, but it is not recommended for large lesions, due to limited visualization of the lesion. Intraoral benign lesions of the maxilla can also be removed using transoral incisions through gingival sulcus. However, when large and deeply located in posterior maxilla, these tumors present extreme difficulty during removal since access is seriously compromised as in the present case. LFIA, as an alternative to a

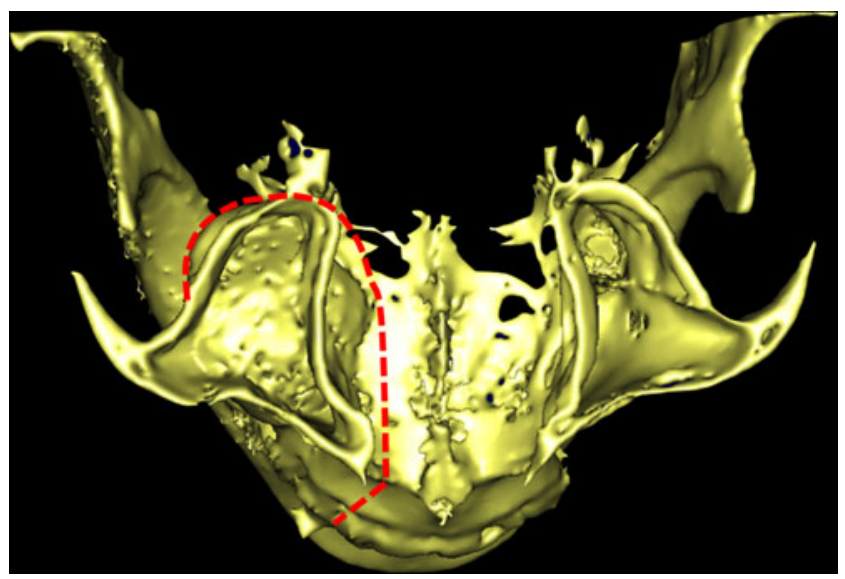

Fig. 3 Representative image of the maxillary osteotomy with a 5-mm bone margin 


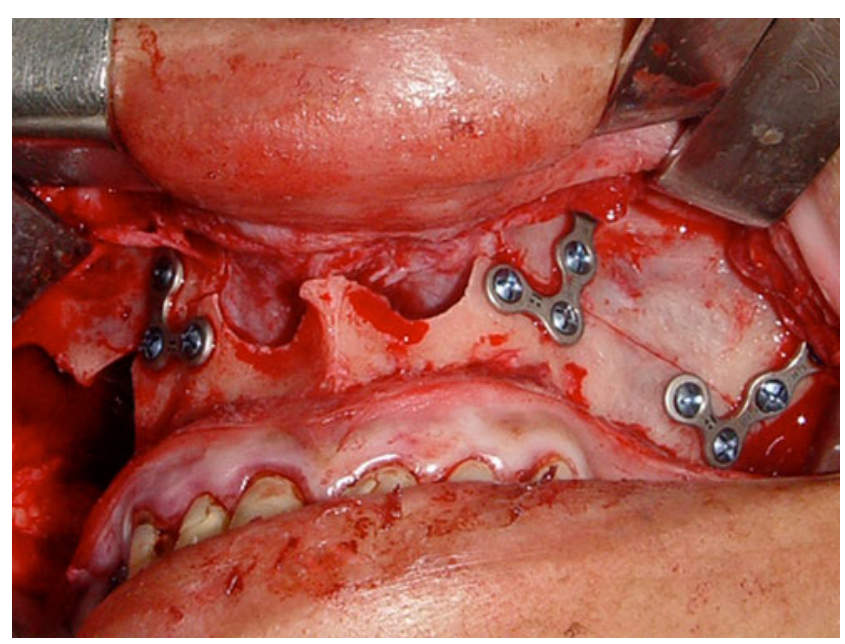

Fig. 4 Placement of pre-modeled fixation plates

Caldwell-Luc approach, provides better access to lesions located in the posterior maxillary region, with a low postoperative morbidity, absence of occlusal change, and good visualization. Furthermore, in cases where the maxillary wall is lost, soft tissues collapse can be prevented [7].

Surgical approach specifically to the OF located in the midface includes the LFIA, Caldwell-Luc access, lateral rhinotomy with medial or total maxillectomy, external ethmoidectomy, and endoscopic surgery [8]. Extraoral access is commonly cited in the presence of extensive injuries [9]. A search in PubMed database for articles in English revealed only 32 cases of benign lesions located in the midface approached by Le Fort I osteotomy in the period between 1988 and 2010 (Table 1). The majority were odontogenic tumors $(n=20)$, followed by fibro-osseous lesions $(n=10)$ and giant cell lesions $(n=2)$. Among the fibro-osseous lesions, only two cases were consistent with OF.

In this case, the decision to use a LFIA was based on the ability to better visualize the lesion margins leading to the establishment of the osteotomies limits and giving sufficient

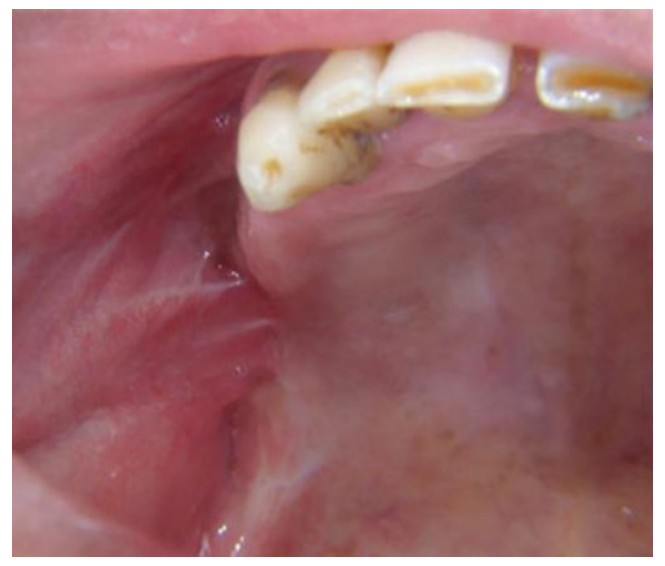

Fig. 5 Clinical aspect after 18-month follow-up period
Table 1 Review of benign lesions located in the middle face approached by LFIA

\begin{tabular}{|c|c|c|c|}
\hline Authors & Year & Total & Histopathological diagnosis $(n)$ \\
\hline $\begin{array}{l}\text { Armstrong and } \\
\text { Bhardway [12] }\end{array}$ & 1988 & 1 & Complex odontoma (1) \\
\hline \multirow[t]{2}{*}{ Alexander et al. [13] } & 1992 & 2 & Complex odontoma (1) \\
\hline & & & Central giant cell lesion (1) \\
\hline $\begin{array}{r}\text { Symington and } \\
\text { Caminiti [14] }\end{array}$ & 1995 & 1 & Ameloblastoma (1) \\
\hline \multirow[t]{7}{*}{ Sailer et al. [5] } & 1999 & 14 & Desmo-osteoblastoma (2) \\
\hline & & & Osteoma (3) \\
\hline & & & Bone keloid (3) \\
\hline & & & Ossifying fibroma (2) \\
\hline & & & Aneurysmal bone cyst (1) \\
\hline & & & Ameloblastoma (2) \\
\hline & & & Myxoma (1) \\
\hline Kademani [11] & 2007 & 1 & Odontogenic myxoma (1) \\
\hline Scolozzi et al. [15] & 2007 & 4 & $\begin{array}{l}\text { Keratocystic odontogenic } \\
\text { tumor (4) }\end{array}$ \\
\hline Korpi et al. [7] & 2009 & 1 & Complex odontoma (1) \\
\hline $\begin{array}{l}\text { Scolozzi and } \\
\text { Lombard [16] }\end{array}$ & 2010 & 12 & $\begin{array}{l}\text { Keratocystic odontogenic } \\
\text { tumor }(8)^{\mathrm{a}}\end{array}$ \\
\hline Present case & 2011 & 1 & Ossifying fibroma (1) \\
\hline
\end{tabular}

${ }^{\mathrm{a}}$ The authors presented a total of 12 cases operated by their service in a period of 10 years, including the four cases reported by Scolozzi et al. [15]

margin to prevent recurrence. The LFIA has been undeniably helpful not only because of the aesthetic potential in using intraoral incision but also because it gives the possibility of reconstruction in a single operation, either by the use of bone grafts, dental implants, or moreover a rotation flap of the buccal fat [5]. It is a versatile technique since the LFIA allows changes in the level of the horizontal osteotomy, so the access can be adapted to the tumor location. A higher osteotomy, for example, in the level of the infraorbital foramen, can be performed when it is necessary to view the orbit floor, ethmoid complex, sphenoid, or skull base [6].

Most complications from LFIA are caused by technical errors that result in undesirable fractures that can be extended to the pterygopalatine fossa, skull base, and orbits causing significant neurovascular morbidity. This can be caused specifically by an atypical morphology of the maxilla, pterygoid plates as hyperplasia, maxillary tuberosity as hypoplasia or aplasia, and maxillary bone density. Those risks can be minimized by careful preoperative planning case [10]. Although the rates of complication associated by LFIA are low, there is the possibility of some problems, such as malocclusion, bleeding, perfusion defects, dental vitality, ophthalmic lesions, lesions, and nasolacrimal fistula development [6]. In our patient, the only complication was a slight oroantral communication in the 15 th postoperative 
day, caused by a small perforation of the intraoral mucosa during the hard detachment of the lesion in its lower aspect, during the surgery, which was promptly treated by making small vestibular flap. Considering that the treatment of OF is curettage, enucleation or lesion excision, our choice of using the LFIA followed by an excision appears to be a versatile, secure, and satisfactory option [8]. The possibility to directly visualize the maxillary sinus area and nasal cavity allowed us to demarcate precisely the osteotomies used, ensuring complete lesion resection [11]. This is very difficult to achieve if transoral incisions in gingival sulcus were chosen. Although the lesion partially obliterates the maxillary sinus, we believe that Caldwell-Luc access [7] should be reserved for small and wellencapsulated lesions, often localized above and inside the maxillary sinus.

Conflict of interest The authors declare that they have no conflict of interest.

\section{References}

1. Waldron CA (1993) Fibro-osseous lesions of the jaws. J Oral Maxillofac Surg 51:828-835

2. Chang CC, Hung HY, Chang JYF, Hu CH, Wang YP, Liu BY, Chiang CP (2008) Central ossifying fibroma: a clinicopathologic study of 28 cases. J Formos Med Assoc 107:288-294

3. Worawongvasu R, Songkampol K (2010) Fibro-osseous lesions of the jaws: an analysis of 122 cases in Thailand. J Oral Pathol Med 39:703-708
4. Barnes L, Eveson JW, Reichart P, Sidranski D (2005) World Health Organization classification of tumours: pathology and genetics of head and neck tumours. IARC Press, Lyon

5. Sailer HF, Haers PE, Gratz KW (1999) The Le Fort I osteotomy as a surgical approach for removal of tumours of the midface. J Cranio-Maxillofac Surg 27:1-6

6. Roy S, Patel PK, Tomita T (2007) The LeFort I transmaxillary approach to skull base tumors. Clin Plast Surg 34:575-583

7. Korpi TJ, Kainulainen VT, Sandor GKB, Oikarinen KS (2009) Removal of large odontoma by Le Fort I osteotomy. J Oral Maxillofac Surg 67:2021-2025

8. Post G, Kountakis SE (2005) Endoscopic resection of large sinonasal ossifying fibroma. Am J Otolaryngol 26:54-56

9. Sun G, Chen X, Tang E, Li Z, Li J (2007) Juvenile ossifying fibroma of the maxilla. Int J Oral Maxillofac Surg 36:82-85

10. Hoffman GR, Islam S (2008) The difficult Le Fort I osteotomy and downfracture: a review with consideration given to an atypical maxillary morphology. J Plast Reconstr Aesthet Surg 61:10291033

11. Kademani D (2007) Le Fort maxillary swing procedure for posterior maxilla tumor extirpation. J Oral Maxillofac Surg 65:10551058

12. Armstrong JE, Bhardwaj AK (1988) Le Fort I down-fracture of the maxilla: application to benign antral neoplasm. J Otolaryngol 17:288-292

13. Alexander R, Weber WD, Theodos LV, Friedman JS (1992) The treatment of large benign maxillary tumors via Le Fort I downfracture: report of two cases and review of the literature. J Oral Maxillofac Surg 50:515-517

14. Symington OG, Caminiti MF (1995) Le Fort 1 downfracture approach for the treatment of a posterior maxillary ameloblastoma. J Can Dent Assoc 61:1048-1052

15. Scolozzi P, Lombardi T, Jaques B (2007) Le Fort I type osteotomy and mandibular sagittal osteotomy as a surgical approach for removal of jaw cysts. J Oral Maxillofac Surg 65:1419-1426

16. Scolozzi P, Lombardi T (2010) Removal of large complex odontoma using Le Fort I osteotomy. J Oral Maxillofac Surg 68:950 951 